\title{
LA ESTÉTICA EN LA ESPAÑA ILUSTRADA: EL IDEARIO MAYANSIANO ${ }^{1}$
}

\author{
Jesús PÉREZ MAGALLÓN
}

A Perry, magister et amicus

El siglo de las luces es el marco temporal e intelectual en que tiene lugar lo que E. Cassirer denomina la elaboración de la conciencia filosófica del arte ${ }^{2}$; lo que M. H. Abrams, utilizando otros parámetros, deseribe como un plantear y responder a las cuestiones estéticas en términos que vinculen el arte al artista antes qut: a la naturaleza externa, al auditorio, o a los requerimientos internos de la obra misma ${ }^{3}, y$ lo que, más recientemente, J. Chouillet ha calificado como un intento de sélucidation du réel sensibles ${ }^{\star}$. Resúmenes apretados y discutibles sin duda. Ese movimiento del pensamiento está encuadrado a su vez en el esfuerzo colectivo de clarificación e liminación que tiene lugar durante el dieciocho encaminado a separar la reflexión teórica occidental del prestigio e influencia de la teología y la metalísica. Fn otras palabras, la centuria ilustrada es testigo de la conformación de la estética moderna, tal y como sería configurada por Hegel - magnus opus - tras los pasos de Baumgarten y, más específicamente, de Kant.

I El contenido de las páginas que siguen ha sido traducido y publicado en catalán bajo el título de -L'estètica en Mayans,, Els Marges, 42 (1990): 100-117.

2 E. Cassirer, La filosofia de la Itustración, 3. ${ }^{\text {a }}$ ed., México: Fondo de Cultura Económica, $1972,307$.

3 M. H. Abrams, El espejo y la límpara: teoría romántica y tradición crítica acerca del hecho literario, Buenos Aires: Nova, 1962, 13.

4 J. Chouillet, L'esthétique des Limières, París: Presses Universitaires de France, 1974, 8. 
No es del caso venir a hacen un breve compendio a centide manuad de lo que es la evolurión de la especulación estétira a lo largo del siglo". El cmpuje que recibe rsa reflexión, por un lado, del satestanismo racionalista - patente an la ohra de: autores como d'Aubignate, Rapin, Buileau o Batteux-y las limitaciones, por el otro, del racionalismo para dar razón de los fenómenos estéticos -incapaz de superar su inlravaloración de la sensación a la imaginación, entendidos como luentes de ilusión y error- son la cara y la cruz de la incidencia que la corripnte racionalista ejerece indisculiblemente sobre el pensamiento estético.

Fil sensacionismo que va de Locke - tras los pasos de Bacon-hasta Condillac. es otra Lendencia que estimula la búsqueda de la especifividad estética a partir de la captatio testhetira, y no de la ratio aesthetica, como atestiguan las olras del P. Bouhours, Du Bos a André. I a pereseprión estélicá rexizre el hallazgro de un órgano -el gusto- que no puede ni debe sey aleatorio o aprichoso, eomo redamará Diderot, y en euyas redes quedará atada e imposibilitada la rellexión sensacionista sobre. lo bello.

Ina creera corriente viene a inlluir, la de: ráz idealista, que produse sus primeros y rotables resultados con Shaficsbury, y que reaparecerá, entroncada tan otros supuestess y con otra expresión, en Winckelmann y su idea de la bellexa ideal -por usar la frase de Fisteban de Arteaga. Ias elaboraciones personales no permiten una clasificación alosoluta e inamovible. Rasgos de una y otra tendencia se entremezelan en los escritos de filósofos, estedas o erítieos. Es la ley de la historia del pensamiento, en la que no existen - ni existirán- construceciones puras y originales ab owo.

En dos grandes ejes conceptuales puede resumirse por reducción y aproximación todo el esfuerzo intelectual, especulativo y sistemático en el rampo de la teoría estólica del siglo XVIII: la idea del genio y la conceprión de lo sublime. Cuando Kant espribe en la Crifrer det jucio que el regenio es la capacidad cspiritual innala (ingenium) mediante la cual la naturaleza da la regla al artex está sintetizando y transformando una multitud de ideas - discutidas en su momento-, aparecidas y contrastadas a lo largo del siglo: la función de la imaginación y la fantasía (Jubos, Addisson), el ante como actividad productora, no mimética

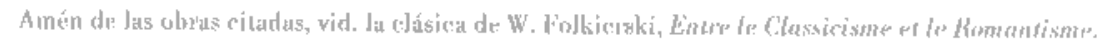

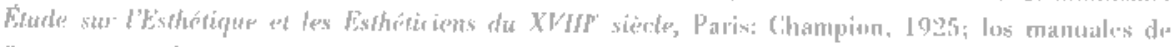

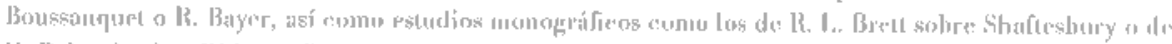

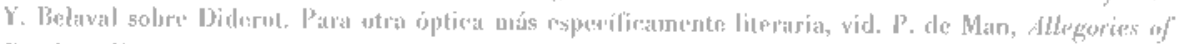

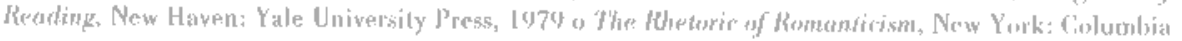
University Press, 1984.

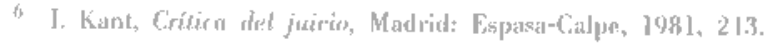


(Shaftesbury, Diderot, incluso Baungarten o Winckelmann) y la función del artista y su relación con la naturaleza, entre otros.

A la teoría de lo sublime, desligada por completo de sus acarreos retóricos (Longino), le dedica Kant todo el libro segundo de la primera parte, sección primera, de la Cirtica del juicio. Pero, con anterioridad, había publicado un opúsculo intitulado Observaciones sobre el sentimiento de lo bello y lo sublime. Con la noción de lo sublime se superarán los límites de lo bello - sin anularla-, insuficiente para explicar la complejidad de determinadas emociones estéticas, y a la que se habían supeditado los pensadores del siglo ilustrado hasia Burke o Mendelssohn.

La idea esencial del desinterés o gratuidad del placer estético, la clara distinción entre pintura y pocsía (contra el horaciano ut pictura poesis), la producción artística como creación o la aceptación del individuo concreto $-\mathrm{y}$ no arquetípico- como héroe son otras facetas irrenunciables de las conquistadas en el pensamiento estético de esta época. No obstante, dos aspectos más creo que merecen unas líneas.

Que las condiciones sociales, económicas o científicas de un momento histórico determinado inciden decisivamente -o tan sólo influyen- en el pensamiento de la época y, más en concreto, en las ideas estéticas, culturales y literarias es una verdad hoy día apenas discutible. Mucho más problemático, sin embargo, es el ámbito en que esa influencia o determinación tiene lugar, su precisión o imprecisión, su carácter y límites, las manifestaciones específicas a través de las que cobra forma.

Factores que indudablemente influyen en la crisis de la estética clasicista y en la formación de la estética subjetiva e idealista, que eclosionará teórica y prácticamente en el romanticismo, son el notable avance en el desarrollo económico de diversas naciones europeas, la liberación irreversible de las ciencias respecto a las ataduras seculares de la religión y el pensamiento teológico - lo que ayuda a poner fin en la creencia de la perfección de la naturaleza como obra divina (ideario de Leibniz-Pangloss), introduciendo la idea de infinitud desde una óptica humana aunque también de perfectibilidad--, el avance y mejora incesante de técnicas que fomentan y son fomentadas por el progreso de la producción mercantil, la creciente asimilación -subterránea o explícita- del individualismo frente a los valores de la colectividad estamental, que se manifestará en las esteras de la economía, la filosofía, la espiritualidad y la política, acompañando el surgimiento de los valores caracterizadores de la sociedad burguesa.

En semejante contexto, la estética clasicista - entendida en su globalidaddifícilmente podía dar cabida a los impulsos emergentes sin resquebrajarse por aquí o por allá. Aquélla, además, en ningún momento ni lugar se erige como adversaria, real o potencial, del poder establecido; bien al contrario, actúa o aspira 
a actuar como aliada eficaz del poder. Alianza, empero, matizada por la coincidencia de objetivos entre la intelectualidad clasicista e ilustrada y el poder (al menos hasta cierto momento de la evolución histórica).

El otro aspecto al que quería referime lo constituye la correlación entre la especulación filosófico-estética y la crítica aplicada al arte. En el siglo de la crítica, ni el arte, concebido como abstracción, ni el arte en sus plasmaciones concretas puede escapar al escalpelo diseccionador de la mente ilustrada con las armas de la razón. La reflexión estética, más que iniciarse a partir de las exigencias que plantea la crítica del arte concreto, surge de las incitaciones inherentes a la filosofía misma. No son las presiones de la crítica las que hacen adelantar la especulación, sino las solicitaciones intrínsecas a un pensamiento que no puede admitir en modo alguno que un campo del quehacer intelectual permanezca cerrado y acotado bajo el rótulo de xpercepciones oscuras o confusas*, como las había llamado Leibniz.

Este impulso fundamental no es incompatible, sino complementario, con el curso que sigue la crítica aplicada, dando origen a una dialéctica en la que los hallazgos o apuntes teóricos surgidos de la especulación sobre la crítica del arte (los casos de Diderot o Lessing son ilustrativos y cimeros) se integran en la reflexión teórica sistemática, en una lógica sin solución de continuidad, a la vez que la especulación autónoma fecunda la crítica del arte. En síntesis, el siglo dieciocho apenas tolera que lo estético permanezca puro e incontaminado frente a las manifestaciones coneretas en que se encarna. Su relación con las artes será constante y característica, bien se parta de los problemas de la crítica, bien de la especulación teórica. La configuración y génesis de la estética será compañera inseparable de la crítica. (Otra rama que brota del mismo árbol, pero aquí inabordable e inabarcable, es la aparición de nuevas formas de creación artística que acompaña - לo precede?- la emergencia de la nueva estética.)

A pesar de que a $P$. Hazard le resultara relativamente chocante que en la época de la transición entre el barroco y la ilustración se manifestase un continuado y renovado respeto hacia las ideas y teorías literarias tradicionales de corte clasicista ${ }^{7}$, en la era de la razón extendiendo avasalladora su radio de influencia por todas las esferas del saber humano, la estética clasicista se ajusta y coincide de entrada con los ideales racionalistas - como sla raison même paseé en lois definiría Chapelain las famosas reglas-, acoplándose asimismo sin dificultad con las corrientes sensacionista y aún idealista - Winckelmann es paradigmático- que dominan el pensamiento del siglo.

7 P. Hazard, La crisis de la conciencia europea (1680-1715). $3 .^{a}$ ed., Madrid: Pegaso, 1975, especialmente la 4." parte, capítulo I. 
Partiendo de las relaciones entre obra, artista, naturaleza y público, M. H. Abrams (16-49) clasifica las teorías críticas -y podemos decir que también las estéticas y literarias - en cuatro tipos: miméticas, pragmáticas, expresivas y objetivas. Las miméticas, de origen aristotélico, pero injertadas con las aportaciones -algo indiscriminadamente asimiladas- de Horario o los comentaristas y preceptistas del Renacimiento, dominan casi ininterrumpida e indiscutidamente, con las matizaciones de rigor, hasta más allá del siglo ilustrado. Las pragmáticas, que ponen el acento en el factor público, coexisten temporal y espacialmente con las miméticas, aunque su arranque sea posterior. Las expresivas se gestan a lo largo del dieciocho, para recibir expresión cumplida a fines de siglo, en el «Prefacio* de W. Wordsworth a sus Lyrical Ballads o en Coleridge. Las objetivas - las que pretenden ser objetivas - serán aportación de las diversas escuelas críticas de nuestro siglo.

Aceptado que el principio fundamental de las teorías miméticas no lo componen las reglas - aunque no sean ajenas a las reglas-, sino la imitación de la naturaleza (mimesis), hay que convenir en que la reflexión sobre lo bello que, antes y después de la acuñación por Baumgarten del término sestética» (gnoseología inferior, ciencia de las percepciones sensibles, ciencia de lo bello), tiene lugar en Europa durante el siglo de las luces es predominantemente clasicista. Esto no puede interpretarse como una afirmación sin paliativos sobre su carácter unívoca y unánimemente clasicista; es reconocer tan sólo que esa especulación se produce bajo el dominio casi indiscutido de lo esencial de dicha estética, el principio de imitación de la naturaleza.

Será el desarrollo y profundización de las diversas corrientes del pensamiento filosófico en el campo estético, que alcanzará su máximo nivel de sistematización en los pensadores alemanes, lo que pondrá sobre el tapete temas como la emoción y el placer estético, el carácter de lo bello y sus límites, etc., cuestionando objetivamente postulados clasicistas. La reflexión estética se produce bajo su hegemonía pero, a la vez, la va socavando y agrietando. Sería fácil establecer un paralelismo alegórico entre lo que ocurre en el dominio de la estética y el proceso de quiebra del Estado del ancien régime y el surgimiento del Estado burgués, tal y como acontece en Francia.

Casos ilustrativos pueden ser los de Charles Batteux y Richard Hurd. El primero, racionalista, aplicando el método deductivo, parte de la imitación embellecedora de la naturaleza como principio válido para todas las artes y demuestra su aplicación práctica en cada uno de los terrenos del arte. R. Hurd, empirista, llega a los mismos principios inductivamente, a partir de los datos y hechos concretos que le ofrecen las diferentes artes. Algo parecido ocurre entre Gottsched y los suizos Bodmer y Breitinger. Incluso el autor de Lakoon y la Hamburgische Dra- 
matrorgie podía afirmar que para producir auténticas obras de arte no hace lalta sujetarse a las reglas y, seguidamente, escrihir que el genio es la más alta conformidad a las reglas, censurando en cunsetuencia al tealro áureo español por sus desmanes desarreglados. El mismo Winckelmann preconizará la imitación de la naturaleza a través de la imitación de las obras griegas, en tanto que adversarios de las reglas se manilestarán a favor del principio de imilación.

Sirvan estas líneas para explicar simplemente, y en alguna medida, el estado del pensamiento estético en la España del dieciocho. Pensadores que aporten algo significativo a la historia de las ideas estéticas hay un número contado, y difícilmente podremos encontrarlos entre los españoles ilustrados. Nombres como los de Shafteshury, Diderou, Rousseau, Baumgarten, Winckelmann, Iessing o Kant entran pocos en un siglo. Dessle una perspeetiva hegeliana, sólo tendría sentido señalar y estudiar el proceso por al due van surgiendo parcial y limitadamente los elementos fundamentales que lograrán un primer nivel de sistematización ya cualitativamente nuevo en Kant y, más allá, en Hegel y su monumental Estéticu.

Frn otras palabris, apreciá y conservar de la historia sólo aquello que cobrará una decrminada significación en la cvolución de la misma - por su aceptación y asimilación-y juzgarlo en base a su función en el devenir histórico. Si lamentablemente se aplicara ese criterio a rajatabla ieuánta pequeña maravilla caería en el olvido, cuánto esfuerzo individual se perdería, cuánto acontecer, cuánta obra, cuánto nombre, sólo porque no consiguieron -o el destino no les permitió- formar parte del curso más que previsible según la dialéctica hegeliana de los acontecimientos ineluctables! Sin negar, pues, lo más evidente -la génesis de la estética subjetiva, idealista y crítica (que, a su vez, será cuestionada y arrinconada en nues(ros días) - hay que reafirmar lo que se ha vuelio no tan evidente: el carácter predominante, durante un siglo preñado de novedades y cambios, de la estética clasirista. Ina estetica que ya entonces estaba destinada a fenecer, aunque no desapareciese, ni desaparezca nunea, el afán de cimentar en la antiguiedad una estélica de valores que se quieren $\rightarrow$ y tal vez lo son- inmarcesibles.

Mientras en Francia, Inglaterra, Italia o Alemania, desde el siglo XVII y acentuadamente desde su segunda mitad, una estética, una teoría y una crítica literaria clasicistas tiene vigor incontestable y se prolongan hacia el siglo siguiente, subsistiendo darante todo el siglo ilustrado y rontemplando los resquebrajamientos que la gestación de la nueva estética iba a propiciar, en España, tras el Pinciano, González de Salas, Pedro de Valencia o Caseales son los representantes de la teoría clasicista, teoría reducida en gran medida a revolotear alrededor de los readores, que son quienes imponen en la practica una estética determinada, en muy pocos casos elevada al nivel de la especulación teórica. La desconcxión y divorcio que se da entre crítica-teoría y creación artísticá es abrumador. 
Desde Cascales hasta los primeros intelectuales que en el dieciocho abordan problemas esteticos, amque no de modo especifico, extenso y pormenorizado, personajes como Nirolas Antenio, con su Bibliotheca Hispetna que, expecialmente en la parte Nowa, is más que una simple bibliogralia, Juan Caramuel y, más adelauke, el dean Martí son los Irasmisores del pensamiento estétion literario dasicista, supliendo las deficiencias, crrores y vacíos que pretendidas retóricas o poéticas sólo ayudan a constatar y calibrar en su verdadera dimensión.

Con los primeros escritos de Mayans, Feijoo y Luzán se retoma la reflexión sobre la estética y la literatura", aunque el estudio de lo bello no será en ninguno de los tres un campo exclusivo, ni siquiera descollante. Cada uno representa una tendencia determinada dentro de una actiud desprendida o insertada en la tradición clasicista. Mayans encarna el retorno al clasicismo bebido directamente en las fuentes de la antigüedad y en sus reelaboraciones renactentistas; lijoo, al situar la esencia de lo belto en el flo sé qués, set eolota al mismo tiempen una perspectiva claramente diferenciada de la de los otros y cierra el paso al avance en una especulación productiva. Leva el sensacionismo hasta un callejon sin salida, puesto que bo consigue alcanzar el principio de esa sengarión, y se conforma con aceptar la impotencia def lombre ante fenomino estétion, reconociendo, como el 17. Bouhours, su incapacidad para ir más allá en la indagación especulativa, aprehensible y transmisible racional y críticamente, de las causas de la emoción estética y de la belleza misma.

Luzán, por su parte, introduciendo y siguiendo el Traité du Beau, de Crousaz, se ubica en una vertiente del racionalismo engastada de posturas sensacionistas, que se compagina con una elaboración plenamente clasicista en lo que toca a la teoría literaria. Pero entre estos iniciales atisbos dieciochescos y la edición de las obras de Mengs por Nitolás de Azara o las hevestigaciones sobre la belleza ieleal, de. Artsaga ${ }^{4}$, transeruren varias decenas de años durante las que lat reflexión estética brilla por su ausencia. Se rompe as rel hilo enductor que, a fuer de optimistas, podría haber dado algún Cruto. Las ideas de Shaftesbury, Didcrot, Rousseatu,

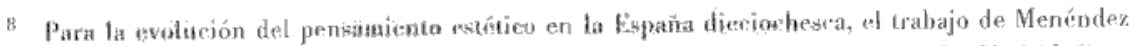

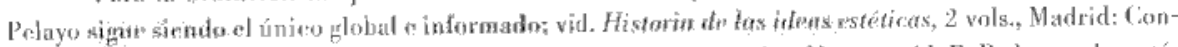

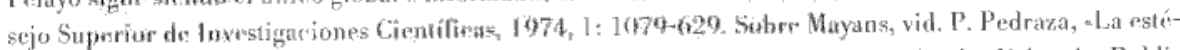

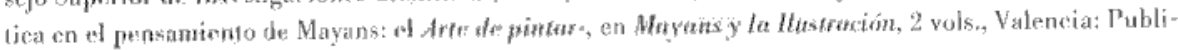
caciones del Ayuntamistilo ds: Oliva, 198I. 1: 237-t6.

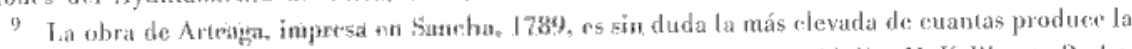
estetica en lispaña durunter of sigho ilustrato. Para mompletar el panorama, vid. Liva M. Kalihuoto Rudat,

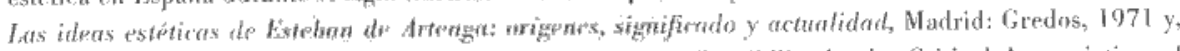
más recientemente, from Preceptive Poetics to Asthetie Sensibility in the Critical Appreciation of Fighteenth-Contury Poetry: Ignacio de Luzán and Fstcban de Arteagas, Dicciocho 11.1 (1988): 37-48. 
Winckelmann o Lessing, por no decir Batteux o Addisson, llegarán tarde, deslavazadas, sin fuerza para germinar una elaboración estética propia, mientras en Europa ese movimiento de ideas y de agitación intelectual va a tcner en Kant una piezu fundamental, prosiguiendo en la escuela filosófica idealista alemana, en sus poetas y creadores, o en los ingleses Wordsworth, Coleridge o Keats. Pero ese es ya otro momento.

Las mismas limitaciones e insuficiencias que caracterizan el siglo ilustrado espan̄ol marcarán la estética en esa época, siendo otra esfera que se escapa así en esa difícil transición entre la edad moderna y la contemporánea. Precisamente en la época histórica en que el pensamiento estético está alcanzando el ser, autónomo e independiente, es cuando más ostensible, flagrante y dolorosa resulta la indigencia nacional en ese terreno. $Y$ ante ello de nada vale recordar a los facolásticos españoles que se anticiparon a Leibniz. En un artículo de prensa escribía Tierno Galván: aCabe decir, con cierta simplificación, que la Ilustración española fue un continuo esfuerzo por evitar que la estética predominase sobre la moral ${ }_{\infty}^{10}$. Y esa voluntaria simplificación es, a grandes rasgos, cierta. Pero también lo es para la Ilustración en Francia o en Inglaterra. La moral, la pedagogía y la utilidad son palabras clave pero que, en esos otros lugares, no impiden el desarrollo y adelantamiento del pensamiento estético. Aquí sí. Tal vez a nucstras exiguas fuerzas intelectuales no les quedaron energías para diversificarse y atender diversos frentes a la vez.

La imitatio en Mayans

Rastrear las ideas estéticas de Mayans plantea un problema importante que no puede ser soklayado con aprioris o aposterioris mejor o peor encaminados. Se trata de la enorme dispersión por sus escritos de breves afirmacioneß, comentarios ad hoc, o simples exclamaciones que van arrojando luz cierta pero lateral sobre su pensamiento. Notablemente significativos, resultan, por esa razón, dos de sus textos: el uno, primerizo, lo constituye la correspondencia que tobre el tema de la imitatio intercambia con el deán Martí, en latín, durante 1721; al otro, tardío, aparecerá póstumo, en 1854, con el título de Arte de pintar, concebido como oración inaugural para el curso de 1776 de la Academia de Nobles Artes de San Carlos de Valencia". El carácter de tales escritos descarta cualquier posible relación o influencia directa sobre intelectuales, artistas o público. Pero son materia primera

\footnotetext{
10 E. Tierno Galuán, -El valor de la estética, El País, 9-9-83,

1. G. Mayane, Arie de pintar, Valencia: Imprenta de José Rius, 1854. En adelante cito por las siglas AP y el número de página.
} 
de valor inapreciable para aproximarse a las ideas estéticas que subyacen y dan impronta a las actitudes y actividades mayansianas en el campo literario o artístico.

Más arriba señalaba la influencia global del deán Martí en la formación intelectual de Mayans, ejerciendo sobre éste una ascendencia continuada desde que comienzan sus relaciones epistolares hasta que muere el sabio humanista. Una ascendencia que el joven valenciano solicita, recibe, fomenta y reconoce públicamente, aceptando del deán una autoridad intelectual sin parangón con ningún otro de sus profesores o amigos. A instancias de Mayans, el deán Martí le escribe, en marzo de 1721, una carta latina en que le expone sus ideas sobre la imitación. Es importante recapitular sobre esa carta, pues en ella se encuentra reflejada la visión que Mayans expresará una y otra vez en el futuro.

Martí pone el acento en el carácter esencial de la imitación como base del arte, afirmando, tras las huellas del Estagirita, que la imitación es origen y fuente de todas las cosas. Y después de dar un salto sin demasiadas apoyaturas explícitas, vuelve a la imitación, aunque privada de la dimensión epistemológica que tiene en Aristóteles y más próxima a la noción ciceroniana de la imitatio, para afirmar que la imitación no es el punto de partida, sino el de llegada para el artista, pues «nada crece solamente con la imitación’"2 para manifestar su convicción de que «el ánimo debe ser empujado hacia el futuro, y las artes deben ser llevadas más lejos por el afán de superación» (24).

De la mimesis, origen de todas las cosas y de toda clase de conocimiento y, por tanto, también del arte, a la imitatio, que puede y debe ser superada, hay una diferencia conceptual profunda. En la mimesis se refleja una clara asociación filosófica entre naturaleza y arte; en la imitatio ${ }^{13}$ se expresa un concepto fundamentalmente pedagógico sobre las posibilidades de acceder a los arcanos de la creación poética, o literaria, mediante un procedimiento primario y elemental -en apariencia- que no contiene la clave de la perfección, pero es un primer peldaño en el aprendizaje

12 G. Mayans, Epistolario. Mayans y Martí, ed. A. Mestre, Valencia: Publicaciones del Ayuntamiento de Oliva, 1973, 26. En adelante cito entre paréntesis el número de la página.

13 Con diferentes aproximaciones al tema, vid. José Jurado, sLa imitación en La poética de Luzán•, La Torre 17 (1969): 113-124; Antonio Vilanova, Las fuentes y los temas del Polifemo de Góngora, Madrid: Consejo Superior de Investigaciones Científicas, 1957, en especial la .Introduccións; A. Vilanova, -Preceptistas españoles de los siglos XVI y XVII, en Guillermo Díaz-Plaja, Historia General de tas Literaturas Hispánicas, 6 vols., Barcelona: Vergara, 1953, 3: 567-692; R. McKeon, -Literary Criticism and the Concept of Imitation in Antiquity», en R. S. Crane et al., Critics and Criticism. Ancient and Modern, Chicago: The University of Chicago Press, 1952, 147-75; A. García Berrio, Formación de la teoría literaria moderna, 2 vols., Madrid: Cupsa, 1977 y Murcia: Universidad de Murcia, [1980]; asimismo, vid. las obras de R. Bray, N. H. Abrams y la clásica de Auerbach. 
de lo que puede y debe ser aprendido. Jil arento de Martó se situará ésencialmente en la imitavión de los mejores escritores, emitiendo algunos juicios sumarios sobre cicrtos aulores lalinns, pero, insistiendo en la idea de que la imitación es principio que tiene que ser superato, alirma que quien pretende llegar al las cimas do la elocuencia no debe conformarse con imitar, sino que adebe analizar más allá y debe esforyarse haria las mejores cosas (26), formulando con nitidez su pensamiento al recomocer, como en el cierre de una elipse, que la mejor imicación de los más insignes modelos no concluye el perfeccionamiento del escritor, pues más allá de allos está de nuevo la naturaleza: aCuando la hayas llenado [al alma] e imprengado de la sangre de los mejores autores, tienes que caminar bajo la tutela de la naturaleza. Pues convisene mo menos imitarla que al artílices (29).

Ia atención del drán, sin embargo, se rentra primordialmente en el problema de la imitación do los mejores modelos. Esta, apunta, no pucde ser algo indiscriminado, puesto que las virtudes de un escritor a autor -al ingenio, la invención, la fuerza y la eapacidad- son bifrontes al igual que Jino. Dependen, por un lado, de la naturaleza; por al otro, de la lomación y el estudio. Es la esencial ecuación naturaleza-arte en la que, en último análisis, todo se redues al primar término. Ciertos rasgos de los escritores modelo no pueden ser imitados, aquéllos que dependen de su naturaleza personal, wa abelleza ingonua y natural, la cual so sustrate a la imitación. (27). Es decir, lo que es especílicamente individeral, las prendas naturalos que cada cual pose - carácter, genio, sensibilidad, temperamento- no st doblegan a ningún lipo de: imilación. Pero esas prendas no bastan para producir la perdeceion. Ser buen escritor, amén de exigir unas condiciones naturales en las que nadie ni nada influye, requiere cstudio, aprendizaje y ejercicio. El autor que róne las prendas naturales que pueden llevarle a la máxima perfección no dolo menosprecjar la imitación, puesto que avanzar por ásta con buen paso presupone una inteligeneia aguda y una hábil prudencia, porque ala imitación es una rosa llena de peligros y dilicultades. (27).

Aconseja Martí distinguir con cl mayor detenimiento y profundidad posibles, sin dejarse engaña por las aparioncias o las primeras impresiones, a qué autov agrada -o agradaría- consagrarse por completo; y luego, qué calidad se considera la mejor en el autor tegido. Por último, no restringirse a un solo modelo, sino ampliar la receptividad en el aprendizaje a los aspectos más destarados y dignos de ser imitados que caracterizan a diferentes autores ya que ninguno puede ser perfrecto y absoluto, eada uno tiene su propia eleganeia y virtud para que la sigamos, sus vicios para que los esquivemos (28). Sólo hay un autor al que jamás se dobe dejar de las manus, Ciuprón, síntesis la más plevada de todas las riquezas de la tradición helénica, de -la Juerza de Demóstenes, la riquesa de Platón, la amenidad de lsócraless (28). 
Su ciceronianismo alcanza tal nivel de convicción que, recordando el ejemplo de Erasmo, quien inicialmente censuró la lengua de Cicerón para convertirse luego en ciceroniano convicto, utiliza el grado de aprecio que se tenga hacia el orador latino como barómetro que mide el mayor o menor avance en el dominio de la elocuencia. Sostiene, pues, Martí que la imitación ha de tener a Cicerón como base indiscutible, pudiendo y debiendo enriquecerse con la asimilación de los rasgos más positivos y sobresalientes de los demás autores, siempre que éstos se ajusten al carácter natural del escritor novel. El ideal de imitación-aprendizaje que propone queda plasmado perfectamente en el caso de Zcuxis, tomado del De Oratore ciceroniano. Para pintar a Helena, Zeuxis tomó de las más bellas vírgenes de Crotona lo más perfecto de cada una de ellas, a lin de componer una figura ideal de belleza. La fortuna de ese ejemplo queda acreditada por su uso en Luzán o Batteux, por no hablar del mismo Mayans, quienes recurren a la misma anécdota para ilustrar concepciones de la imitación no siempre coincidentes.

Concluye el deán relativizando sus propias palabras, poniendo de relieve que los principios no son nada sin la práctica, hasta el punto de que los antiguos dudaban de si la elocuencia estaría contenida en el estudio o en la práctica. Realzando la importancia del ejercicio - en lo que le seguirá Mayans-, pone en tela de juicio los otros valores y supuestos sobre los que antes se ha extendido.

El 29 de marzo del mismo año, 172l, Mayans contesta la aerudita y elegante carta (32) del deán, que ha leído con verdadero placer. A las ideas que aquél ha expuesto, sólo puede responder que está dispuesto a seguir su opinión, distinguiéndolo como «el más sabio de cuantos existen en esta época* (32). Pone en la cabecera de su respuesta la más rotunda afirmación de la prioridad de la naturaleza en todo lo que se refiera a la imitatio, puesto que la imitación de los mejores autores sólo tiene sentido gracias a la imitación de la naturaleza, es decir, se imita a los autores porque es una vía, la mejor sin duda, para acercarse a la imitación de la naturaleza; “por lo demás, mucho mejor será emular la negligencia de la naturaleza que seguir la exacta diligencia de otros» (32).

Acepta, con el dén, que hay aspectos que dependen de los rasgos naturales del autor y que resultan por ello inimitables. Esto no es óbice para iniciarse en la imitación de los modelos con el ánimo indesmayable de aspirar a su superación o, como él escribe, whemos de escoger el mejor orador, y unidos a sus pasos dirigirnos a la cima de la elocuencia (34), complementando lo que había dicho antes: «hay que entablar una gloriosa batalla con cierto afán de victoria junto a los hombres más eruditos" (33). Coincide con el juicio del deán sobre la eximia calidad de Cicerón, sin discusión el mejor orador de cuantos hubo en el pasado, según el consenso de la opinión crítica de todas las épocas, confirmando que ssolamente éste ha de ser imitado por encima de los demás» (34). La visión sincrética que el deán 
había expuesto sobre la imitación de los mejores rasgos de los diversos escritores, teniendo como base a Cicerón, es algo que el joven Mayans ya había entrevisto:

yo siempre le he tenido por encima de todos los escritorea, y tú me propones que yo le imite; sin embargo, lo hago de tal manera que no pienso en él sólo, sino que de los escritores áureos, extraeré aquello que hayan dicho graciosa y brillantemente (34).

Más adelante, el todavía estudiante de Derecho recuerda que nunca creyó asociada automáticamente imitación y elocuencia, exponiendo sus razones esenciales:

\footnotetext{
Pues ante todo, el ingenio, la fuerza y el talento se sustraen de la imitación. Luego la dialéc:tica nos enseña la razón de investigar los argumentos; el asunto mismo y la azidua lectura nos da la abundancia de éstos; un juicio cabal nos prescribe el orden de su colocación; la relúrica uns enseña el ormato del discurso; el ejercicio produce facilidad de hablar. Quien posea todo esto será llarnado elpcuentísimo y sin duda lo será. Con todo źqué lugar ocupa alli la imitación? (35),
}

interrogándose sobre la eficacia de la imitación y su funcionalidad en el caso de quien a una aguda inteligencia y ágil juicio añade el dominio de las lenguas eruditas, de la dialéctica, de la filosofía y de las demás disciplinas. Pero, como dije en páginas atrás, esto no conduce a la elocuencia espontánea, puesto que no debe olvidarse que entre esas disciplinas con las que debe estar familiarizado se encuentra la retórica y demás artes. Por supuesto que quien posea estos atributos y conocimientos podrá alcanzar una elocuencia no vulgar. (37) y será tenido entre los elocuentes. Por el contrario, ten el que estas cosas no estén, aunque esté presente una asidua imitación, nosotros le creemos verdaderas bagatelas. (37). Así toma carta de naturaleza en el dieciocho la premisa estética y teórica del clasicismo que resume la perfección de la obra en la síntesis equilibrada entre imitación de la naturaleza, atributos naturales, aprendizaje, estudio e imitación de los mejores modelos.

Hasta qué punto las ideas expuestas por el deán van a ser asimiladas por Mayans lo revela tanto el contenido de la carta con que le responde como lo que ya se ha venido indicando sobre su pensamiento literario y, por supuesto, sus principios estéticos. No es preciso subrayar la relevancia que tiene el escrito del deán como medio de transmisión de un ideario y unas convicciones hondamente clasicistas, decantadas por la frecuentación del mundo cultural pagano y de los grandes espíritus renacentistas, entre los que Erasmo ocupa a todas luces un lugar preeminente. Menos necesario aún poner de relieve la fuente de que manan las ideas de Mayans sobre el tema desarrollado por el deán en su carta.

En esta temprana correspondencia entre maestro y discípulo, aparecen ya claramente delimitadas algunas nociones axiales de lo que será la estética mayansia- 
na, especialmente en lo tocante a la idea de la imitación. Superfluo por obvio repetir aquí lo que ya dije al hablar de los principios que sostiene sobre la prosa: su carencia de originalidad, expresada y reivindicada abiertamente. En cuanto a la influencia de las palabras que le dirige Martí, basta recordar que referencias concretas e incluso ejemplos que aparecen en estas cartas se repetirán a lo largo de los escritos de Mayans. Valga como ejemplo lo que le escribe a José Borrull a propósito de la carta de Feijoo ellocuencia es naturaleza y no arte»:

Las prendas naturales, como el ingenio, la vehemencia y otras semejantes, no son imitables, pero la propiedad, la colocación de las palabras, el método de las oraciones es imitable, y tan imitable que no se adquiere naturalmente ni por otro medio sino por el de la imitación $^{14}$,

argumenta con palabras directamente emparentadas con la correspondencia a que aludía.

Reiteradamente afirmará Mayans la preeminencia de la naturaleza como punto de referencia último y como guía de todo artista. Afirmaciones como la que hacía en su respuesta al deán, sosteniendo que es preferible equivocarse con la naturaleza antes que acertar siguiendo a algún autor determinado, subyacerán y aflorarán en todas sus opiniones sobre la imitación, y se harán más insistentes cuando se refiera a dicho tema en cualquiera de sus obras. La naturaleza ses la que en todo debemos imitar y seguir ${ }^{15}$, escribe en El orador christiano. Sin embargo, y como quiera que en ningún momento se plantea una mayor profundización filosófica o estética sobre la mímesis, la imitación de modelos, de consecuencias prácticas y pedagógicas mucho más inmediatas y tangibles, pasa a primer plano en sus trabajos literarios.

Qué cosa sea para Mayans la naturaleza, objeto primordial de la imitación y principio seguro que debe conducir al artista, es algo que sólo por deducciones a partir de diversas referencias puede deducirse. Aristóteles veía en la naturaleza «la esencia de los seres que poseen en sí mismos y en cuanto tales el principio de su movimiento» (Metafísica 4, 1015). Mayans, que no contempla la naturaleza con el mismo espíritu filosófico y científico del Estagirita, ve en el orden natural que nos rodea la obra suprema de Dios. La naturaleza se presenta a sus ojos como una sublime perfección generada apor aquella universalidad de causas eficacísimas que Dios creó y ordenó» (AP 11).

14 En A. Mestre, El mundo intelectual de Mayans, Valencia: Publicaciones del Ayuntamiento de Oliva, 1978,160 .

15 G. Mayans, El orador christiano, Valencia: Antonio Bordázar, 1733. En adelante cito con las siglas $O C h$ y el número de página. 
Es.s. pues, la partivipación o intervención derisiva de Dios en la freación da la naturaleza la que le conliere en principio el grado de perlección que posee. El artista, al intentar imitar la naturaleza, se encuentra no sólo ante algro perfecto, sino ante la labor del supremu antílice, del hacedor divino, cuya obra, precisamente por haber salido de las manos de Dios, es perfecta y, por lo tanto, irrepresentable por +1 artista. Cualquier productión del hombre, al imitar la naturaleza, quedará siempre muy lejos de la obra divina; por perfecta que pueda parecer, nunea alcanzará la pertección sublime del original. Así, afirma que acn eualquiera cosa natural en que busquemos las perferciones, al querer imilarlas nos quedamos muy atrás; y cualquier imitación es inferior a la perfección natural, y siempre admite anmentow (AP 89). No pone en duda la capacidad del artista para producir una obra perfeota, pero establece como premisa mayor la superioridad indiscutible e indiscutida do la iuperfecible obral de bios - naturaleza - frente a la obra del hombre - arte-. Hay, pues, una perleceión - la Perfección- que es inacesible al hombre por el hea ho mismo de su humanidad: a dos pintores, como son hombres, no puede llearal a la perfeceión cuando imitan en todo a la naturalezan (50-60), escribe en Arte de piturit.

Fsa impotencia estencial y consustancial al hombre para imitar la perfección de la naturaleza no debe concluir en la rusignada accptación de sus limitaciones. Por el contrario, el artista - o el que pretende llegar a serlo- ha de estudiar como nadie, con tenacidad y minuciosidad, cl libro de: la naturaleza, aspecto en el que, entre Ios pintores, I onardo da Vinci resulta maestro insuperado. lis artista se incuentra así encajonado entre dos límites precisos: de un lado, la perfección infinita de Dios y su obra; del otro, su propia incapacidad para alcanzar jamás esa perlección. El hombre, cono un cierto y renovado Sísifo, dche estudiar la naturaleza con perseverancia, tratando de imitar su belleza pero sabiendo que no podrá lograr la perfección, vedada como lo pstá por su misma humanidad. la naturaleza, perfección suma, permanece ahí, ello como paradizma de toda producción artística, forzosamente inalcanzable y buscada. Elemento siempre de relerencia para juzgar la obra, a sabiendas de que ninguna producción anlística conseguirá equipararse a ella.

La perferción de la naturaleza, sin embargt, no es la de todos y cada uno de los objetos, seres y partes que existen en ella o que la constituyen. Mayans reconoce y admite quo en la naturaleza uxisten adelectos", es decir, alteraciones de las cosas perfectas que Dios croó. Perfección global, pertección del todo que no signilica perfeceión de Lodas y carla una de sus partes. bintenta así integrar las certezás aportadas por la viencia sobre la imperfección del mundo en su optimismo eristiano de perfección natural por la divina mana creadora? En tanto la naturaleza fucra concelida como perfecetión absoluta, el objetivo máximo y único del artista 
había de ser la imitación de lo perfecto material y particular existente a su alrededor. El arte no tendría otra función que la de ser mera copia, es decir, un intento de captar y representar, ni más ni menos, que lo perfecto. En cuanto se admite la imperfección de la naturaleza, se abre el margen suficiente para la renovación de la teoría de la imitación universal en oposición a la imitación particular.

En la correspondencia con el deán Martí, éste hacía una aplicación peculiar de la imitación universal a la imitación de los modelos trayendo a colación el ejemplo de Zeuxis. Una idea semejante expresaría Mayans al aconsejar que se procure «imitar, fija más la mente en la perfección universal que requiere el arte, que en la particular observación del artificio de algunos ${ }^{16}$, intentando una síntesis entre la perfección universal, que sólo puede entenderse como concepto aplicable a la naturaleza en su todo, y el artificio particular «de alguno", sólo comprensible si atañe al modelo. Zeuxis aparece aquí también como ejemplo simbólico que ilustra y justifica una actitud ${ }^{17}$. Los términos en que expone Mayans la anécdota del pintor griego son claros: se está refiriendo a la perfección en la imitación de la naturaleza que se logra fecundando la idea del artista con las perfecciones parciales de objetos reales y concretos existentes en la misma naturaleza.

Las expresiones con que se habla de la imitación parecen repetirse a lo largo de muchos siglos. Con palabras parecidas hablará Winckelmann en sus Gedanken ${ }^{18}$, y es aquí donde, junto al retorno hacia el gusto antiguo, formula la labor creadora del artista al ver en las obras y esculturas griegas la realización de la idea del artista, y no sólo la imitación de la naturaleza, aunque esa idea sea impensable e inseparable de la realidad concreta de la belleza de cuerpos jóvenes reales de gimnastas y atletas. Embrionaria y sintéticamente, esa opinión parece latir en las palabras de Mayans.

Al escribir, más adelante, su Arte de pintar, volverá sobre el mismo tema. El pintor, o el aprendiz de pintor, no debe conformarse con imitar una pintura hermosa, sino que debe procurar superarla «imitando la perfección de la naturaleza, y enmendando los defectos que en ella encuentre (17-8). Pero ¿cómo corrige el artista los defectos que encuentra en las cosas particulares existente en la naturale-

16 G. Mayans, Oración que exhorta a seguir la verdadera idea de la eloqüencia española, Valencia: Antonio Bordazar, 1727, 11.

17 Asi lo había narrado Mayans; ·Habiendo de pintar la imagen de la bellísima Helena, no quiso escoger por ejemplar una sola niña, aunque muy hermosa; sino que, fecundando su idea con la hermosura de cinco las más bellas vírgenes que a la sazón había en la ciudad de Croton, logró ser émulo de la naturaleza misma. (OE-1727 11-2).

18 J. J. Winckelmann, Réflexions sur l'imitation des cutres grecques en peinture et en sculpture, ed. bilingüe, Paris: Aubier, 1954, 95-101. 
za? Para Mayans, esiguiendo la perfección ideal que es mayor o menor, según la penetración y observación de los hombres que contemplan y observan la naturaleza» (17). Esa dialéctica aparentemente contradictoria pero íntimamente coherentc por la cual la idea, que surge de la observación y contemplación de la naturaleza, perfecciona los defectos de la misma naturaleza se reafirma en otro lugar, donde escribe: si $_{\mathrm{S}}$ el objeto del autor es ideal, y existe clara y distintamente en su entendimiento [...] únicamente el pintor puede observar si [la pintura] es perfecta o no; porque él solamente sabe cuál es su idea, la cual, por extraña que sea, se compone de las que tiene de varios objetos (9-10). En otras palabras, Mayans parece haber expresado la fuerza creadora de la idea del artista. Pero el recurso sistemático a su relación con la naturaleza parece alejarlo de Winckelmann o de las especulaciones de Arteaga. En él, al no llegar a conferir a la idea la capacidad creadora inmediata, la noción de la imitación fluctúa entre la abelle nature de Luzán o Batteux y la sbelleza ideals del alemán.

Es cierto que Mayans no se preocupó de una manera contimuada por los problemas estéticos, y ello se percibe en la lectura de sus comentarios sobre el tema. Pero de eso a saldar sus ideas con una frase lapidaria, entre burlona y despectiva, como hace Menéndez Pelayo, hay un abismo. Cuando afirma Mayans que las pinturas más celebradas han sido las más engañadoras, está rebatiendo -o comentando- a Lucilio, quien aseguraba que en los estantes de los pintorcs no había nada que fuera verdad. Lo relaciona con la perfección en la imitación de la naturaleza y con el esfuerzo preciso para distinguir lo verdadero de lo fingido, pues si la obra ha de ser semejante a lo imitado, la perfección de aquélla puede plantear dudas sobre cuál sea el objeto real y cuál la obra de arte.

Deducir de ese comentario su incapacidad para reflexionar sabre arte o estética es llevar las cosas un poco lejos. Lo que, por supuesto, tampoco le convierte en un térico avanzado en dichos terrenos. Su idea de la belleza es esquemática. En lo que toca a las artes plásticas o espaciales, se reduce a valorar la simetría y la proporción. Sólo con el juego de esos dos elementos obtendrá la obra artística lo que Mayans llama hermosura, donosura, gracia o belleza. Y de modo primario percibe y expresa la percepción del placer estético, o sea, acierta perfección que excita la vista y estrechamente la deleita, la cual no es repugnante a la naturaleza, sino que se le sobreañade para acomodarse más al agrado y deleite del que la mirà (AP 154).

El carácter ya desfasado respecto a lo que se viene escribiendo en Europa sobre la belleza o el placer estético no precisa mayor encarecimiento. En España, si dejamos de lado las páginas que dedica Luzán en La poética a la belleza en general, a la belleza en la poesía y a la verdad ${ }^{19}$, aún no ha aparecido la obra de Ar-

19 Me refiero en especial al eapitulo VII del libro segundo de La poética. 
teaga. Mayans, a su manera y por su camino, pretende restaurar el gusto clasicista formulado con la integración de elementos filosóficos que provienen del cartesianismo y del sensacionismo, pero que esencialmente arrancan de su conocimiento de la antigüedad y de sus extensas lecturas. La postura tolerante que muestra ante el desnudo, por ejemplo, basada más que en la suprema dignidad del cuerpo humano en la «naturalidad y gracia $(A P 47)$ de sus perfiles, quiere apuntar algo moderadamente moderno. Pese a ello, no avanza mucho más allá.

En relación con el tema de la imitación de la naturaleza, dos aspectos más conviene señalar. El primero es que la representación o imitación de la naturaleza recibe una justificación, aparte de la religiosa, digamos filosófica, por cuanto la naturaleza no sólo es creación divina y realidad, sino también verdad. «Los que imitan a la naturaleza, directa o indirectamente, representan la verdad ( $A P 60)$, afirma resueltamente, integrando así dos de los elementos fundamentales que constituyen la ecuación en que puede resumirse la estética clasicista: lo bello y lo verdadero. El tercer elemento de la ecuación, lo bueno, aún no formulado, es una constante en el pensamiento mayansiano ${ }^{20}$.

El segundo trata de la vinculación entre la imitación de la naturaleza y el concepto de arte. Asentado que la naturaleza precede al arte, éste no es otra cosa que «una observación de las perfecciones de aquélla reducidas a método* (OCh 212). El arte es, pues, la junta de preceptos (que resumen la experiencia de numerosos artífices y es, por tanto, una expresión diferente de la misma naturalea) en un campo determinado de la creación artística.

La importancia de la naturaleza, de su estudio, del cada vez mayor conocimiento de sus secretos, de sus formas, de sus perfecciones y defectos, viene subrayada insistentemente en los escritos mayansianos. Al extremo de que en ningún momento puede imaginarse que ese estudio sea incompatible con cualesquiera de los pasos o procedimientos que el artista debe utilizar o seguir para alcanzar la perfección en su arte: «Verdad es que el estudio de la naturaleza no se opone a la imitación, ni a las ideas compuestas en la imaginación, ni a la de las pinturas de los más insignes artífices, ni a la de sus copias. ( $A P 17)$, escribe, formulando con nitidez la escala de valores en que funda el proceso de la producción artística.

Pero si la naturaleza es la que en todo hay que seguir e imitar, ¿qué lugar ocupa la imitación de los mejores autores, sean escritores, pintores o escultores? En El orador christiano expone con la más absoluta trasparencia su pensamiento al respecto:

20 Recuérdense los versos de Boileau, Rien n'est beau que le vrai, le vrai seul est amaible. 
Por eso rnfargo yo tiulo la ubservacióne e imitación de los antiguos, porque ellus (mas sabios en esto que los modernos) en todo procuraron atender y expresar la naturaleza y la verdad; o por medio de una sencilla narración de los sucesos, como los historiadores; o por medio de las causas, como los fílósolos; o por medio de la imitarión, comó los poelas; a por medio de las contiendas y conmociones de los ánimos, conı los oradares. Y así los antiguos y primeros maestros de las cicncias (eada cual en su profesión) se hicieron tanto más dignos de alabanza e imitación cuanto por medio de ésta más peosuraron allegarse a la perfección de la nacuraleza $(103-4)$.

Añadiendo, como apéndice, en Arte de pintar que ues muy conveniente imitar a los mejores artistas, porque ordinariamente, por medio de ellos, indirectamente se imita la naturaleza: $(60)$.

El parentesco intelectual y anímica de estas palabras con las que emplea Winckelmann para justificar y fomentar la imitación de los antiguos es más que evidente. Pero tampoco se diferencian en exceso de las que ulilizaran Cicerón o Quintiliano en la antigüedad, Scalígero o el Brocense en el Renacimiento, o los incontables preceptistas y teorizadores del clasicismo francés, desde Chapelain hasta fines del XVII, incluidos los modernos Fontenelle o Perrault.

Retornar a la antigüedad o al Renacimiento no tiene, por supuesto, un carácter indiscriminado. No responde a un deseo de vulver la vista atrás en un intento desesperado de huir del presente y hallar refugio ante las presiones acuciantes y cada vez más hostiles del medio. Ni será un respaldo teórico del plagio, copiando los mejores logros de los antiguos. Se trata de volverse hacia quiencs más destacaron en el ejercicio de un arte o ciencia para asumir sólida y consecuentemente los hallazgos de la tradición cultural en que cstamos anclados e inmersos para, desde. ahí, proyectarse hacia adelante en su progreso y perfeccionamiento. Por ello aconseja: «imitad [...] en cada perfección al que ha sido más eminente en ella* ( $A P$ 187), extendiendo la misma idea respecto al aprendizaje de la lengua y la literatura, puesto que su perfección alógrase oyendo, leyendo e imitando. Oyendo a los que hablan mejor; leyendo e imitando a los que han escrito más elegantemente (OCh 168), y palabras parecidas usa refiriéndose al estudio y aprendizaje de la pintura.

Distingue Mayans entre dos tipos de imitación de modelos, ala una es propia de aprendices, que únicamente han de imitar, copiándolo todo con puntualidad; la otra es propia de los adelantados en la pintura, que han estudiado bien la naturaleza y que copian con deseo de mejorar lo ya pintado (AP 18). Y, de modo paralelo, señala dos tipos de imitación en el estudio y práctica de la lengua. La una es "acomodando a su asunto las frasis de otro- (OCh 18), como hizo Clemente IX siguiendo los pasos de I eón X. Este procedimiento puede conducir con facilidad a olvidar xel vigor de la sentencia, poniendo mayor atención en las palabras. (OCh 47). La otra manera consiste en 
leer tanto a un autor que venga uno a naturalizar en sí aquel modo de discurrir, de proponer, distribuir, probar, amplificar, rechazar, hablar y mover, sin valerse jamás de la misma contextura de la oración, pero sí de semejante propiedad, corriente, majestad, esplendor y gracia (OCh 47).

No es cuestión, por tanto, de copiar a la letra, ni de escribir como los centonistas, sino de procurar emular a los autores elegidos como modelos *así en el método como en la valentía del decir» (OCh 48). Esa asimilación del espíritu y la forma del autor escogido es la mejor manera de imitar, ayudando a la formación y progresivo perfeccionamiento del propio estilo. Para iniciarse en este modo de imitar, Mayans aconseja que se tome el mismo asunto de aquel a quien se desea imitar (que debe ser siempre un autor de calidad contrastada), ejercitándose en amplificar lo que en él sea breve, en resumir lo prolijo, en ordenar lo que no esté bien dispuesto, en seguir y respetar lo que no deba modificarse, en mejorar lo que se preste a ello y en repetir lo inmejorable. Asimismo, es aconsejable traducir las mejores y más elocuentes piezas de otra lengua, y muy en especial de aquélla en que «la invención y arte está más recogida* (OCh 51), es decir, la latina. Traducir, por ejemplo, a Salustio o Tito Livio para comparar y cotejar luego con otras traducciones de los mismos textos.

Como es fácil suponer que quien se está iniciando en este tipo de imitación se encuentra en el primer nivel de su aprendizaje (sea orador, escritor o pintor) y carece de criterios preeisos para poder juzgar sobre la calidad de sus propios trabajos, en su corrección y adiestramiento ocupará un lugar fundamental la figura, de origen horaciano, que Mayans llama el «censor», cuya función consistirá, como es lógico, en señalar los errores, elogiar los acierios, aconsejar y ayudar al novato. El papel de censor lo puede ocupar "cualquiera que tenga el genio crítico» (OCh 51), lo que no es pedir poco.

Este tipo de imitación es concebido como punto de arranque en la formación del artista, y en absoluto como criterio fijo e inmutable de perfección artística. La imitación, entendida como asimilación e identificación con un autor determinado, pero enriquecida con las virtudes de otros, no sólo no impediría sino más bien facilitaría que ahabiendo hecho y formado cada cual su estilo propio, dejase después seguir su genio, sin atarse a éste ni al otro, sino eligiendo los mejores libros y valiéndose de todo aquello que fuere más del caso" $(O C h 49)$. Nada tiene que ver esta actitud con la idea más o menos difundida sobre una postura dieciochesca de imitación servil de los antiguos. La imitación es el primer paso para lanzarse a la superación de los mismos autores imitados. El objetivo, la meta del discípulo es aventajar al maestro, siempre que se den en él las prendas naturales y la dedicación. «Así se hace uno en el arte émulo del otro, llevando siempre el ánimo de vencerle, $o$ a lo menos de igualarle» (OCh 50). Después de esa fase, el cultivo de los 
estudios, la lectura, la meditación y las dotes personales harán posible y necesaria la imitación directa de la naturaleza. Como le aconseja a Antonio Burriel, se trata de que aantes sea un Horacio que imitador de él $\star^{21}$. He ahí el objetivo verdadero y último de la imitación y, por tanto, de Mayans en su labor en pro de la restauración de las letras: que España vuelva a producir artistas sublimes, Horacios y no imitadores, como ya había sucedido en los siglos de esplendor.

La imitación de los modelos -en la que Mayans destaca por ser el primcro en el dieciocho que preconizará de una manera sistemática, y facilitará los medios para ello, la imitación de los mejores autores españoles de los siglos anteriores a diferencia de lo que había sostenido un Du Bellay o un Scudéry en Francia ${ }^{22}$, emparentada con la imitación de la naturaleza, cobra el valor de una propedéutica y una pedagogía para despejar el acceso y favorecer la penetración en los scerctos no tanto teóricos como prácticas del arte. En modo alguno se basta por sí misma ni se autojustifica. La simple imitación (copia o asimilación) es insuficiente, aunque necesaria. Si el artista tiene genio, la cultura y el gusto precisos, a través del ejercicio debe ir a la busea en símismo y en la naturaleza de los materiales que le pueden convertir en autor parangonable con las grandes figuras del pasado.

Verosimilitud. Decoro. Función de la obra de arte

Tanto la imilación de la naturaleza como la de los mejores autores deben ajustarse y respetar los supuestos de verosimilitud y decoro. Ambos conceptos aparesen estrechamente enlazados. En su descripción de los rasgos de El orador christiano escribe: «Ho: procurado observar el decoro, haciendo que fabres sólo enseñe a Lucrecio tales cosas que sean dignas de practicarse en la cátedra del Espíritu Santo, con tal verosimilitud que se puedan enseñar en una conversación. (XXVIII). No tiende a entrar en arduas o minuciosas lucubraciones sobre la verosimilitud. Parece como si fuera algo tan elemental que no impusiera mayor detenimiento. Así, ante un párrafo del Quijote, exclama alborozado: ai Nimiedad sencilla y graciosa! iVerosimilitud admirable y sin igual! $\star^{23}$.

No obstante, cuando menciona las características que debe reunir la narración y afirma que una de ellas ha de ser la verosimilitud, explicita, aunque brevemente, lo que entiende por ella. Lo verosímil es igual a lo probable, y la narración

21 G. Mayans, Epistolario. Mayans y Burriel, ed. A, Mestre, Valencia: Publicaciones del Ayuntamiento de Oliva, 1972, 605.

22 Vid. R. Bray, La formation de la doctrine classique en France, Paris: Hachette, 1927, 177.

23 G. Mayans, Vida de Miguel de Cervantes, ed. A. Mestre, Madrid: Espasa-Calpe, 1972, 44. 
será verosímil «si se cuentan las cosas según pide su naturaleza, las costumbres de los hombres y opinión común, y se manifiestan las causas de los consejos y razones de las cosas, de suerte que nada se deje, ni refiera hecho sin causa, sino que sea tan evidente que no sea menester indicarlas (OCh 9l).

En dos elementos, pues, se basa la verosimilitud. Por un lado, en la congruencia de lo narrado con la lógica misma de las cosas, con su naturaleza. Puesto que representar la perfección de la naturaleza es imposible, dada la incapacidad esencial debida a la oposición hombre-Dios, inventor-creador, lo que sí puede y tiene que exigirse a la imitación es que respete coherentemente las exigencias que impone la esencia de las cosas imitadas. Por el otro lado, en lo que Mayans llama alas costumbres de los hombres y opinión común». Lo verosímil aparece aquí, dentro de la tradición aristotélica, como lo que parece creíble y resulta aceptable para la opinión común.

Delimitar en términos abstractos lo que sea la «opinión común» es imposible. No acepta la sincronía. La opinión común es por esencia histórica y social, evoluciona con los tiempos, cambia con las culturas y está en función de qué grupos o sectores sociales sean los considerados dignos jueces para emitir la opinión que debe ser tenida en cuenta. Es, en otras palabras, un problema de autoridad. En última instancia, la opinión común no es sino el común denominador por el que la ideología dominante (que es la de la clase dominante) se convierte aparentemente en ideología natural, sin límites ni rasgos específicos de clase.

Lo verosímil es concepto clave en la poética y retórica aristotélicas. R. Barthes señaló agudamente cómo ese concepto, a nivel metodológico, basa una concepción del arte y la oratoria supeditada al sentido común y puede sustentar una determinada visión de la cultura de masas, dependiente a su vez de las ideas políticas del Estagirita $^{24}$. Autoridad y adscripeión ideológica de clase se juntan. Ese sentido común, esa opinión común no surge espontánea del espíritu anónimo y creador (poéticamente) del pueblo, sino que, respondiendo a los intereses de los sectores dominantes de la sociedad, llega a hacerse asimilable -o a asimilarse por múltiples vías- para la mayoría de los grupos sociales.

Al considerar la sabiduría como valor primordial, para Mayans sólo es admisible la opinión común de los doctos, no de los aristócratas - por el simple hecho de serlo-, ni del vulgo. Rasgo significativo del modo en que influye la adscripción ideológica de quien formula su idea de la opinión común es que Mayans, por

24 Vid. R. Barthes, Investigaciones retóricas, 2 vols., Barcelona: Ed. Buenos Aires, 1982, 1: 18; Iambién R. Barthes et al., Lo verosímil, Buenos Aires: Ed. Tiempo Contemporáneo, 1970. El conjunto de artículos allí recogidos es de sumo interés. 
ejemplo, no pueda aceptar que ésta atente contra los valores de la religión católica. Lo verosímil es, por tanto, un terreno en el que confluyen la aspiración a la coherencia artística y los valores de coherencia social y moral.

Por este camino se relaciona con el concepto de decoro. A pesar de que el eximio y áulico Goethe se hurlara del uso - y abuso- que los franceses habían hecho del decoro en sus teorizaciones preceptivas, creyendo inadecuado que se aplicara una idea propia de las conveniencias sociales a la esfera del arte, el decoro (lo aptum) es, en la tradición poético-retórica, algo más rico de lo que quiso hacer creer el intelectual de Weimar, por otra parte profundísimo conocedor de esa tradición. H. Lausberg ${ }^{25}$ ha establecido una sugerente asociación entre la concepción platónica del prépon (en Gorgias), considerado como la virtud de las partes para eneajar en un todn -y desarrollado por Quintiliano en sus dos facetas de decoro interno y decoro externo- y la relación ética individual-ética social a la que debe acomodarse la obra del artista.

La insistencia en que, al initar la naturaleza, el artífice debe guardar el decoro antes que cualquier otra cosa es una constante sobresaliente en los escritos mayansianos 26 . Ia importancia que le concede es tal que llega a afirmar, comontarido el De Doctrina Christiana de San Agustín, que la decencia o decoro es ala suma del arte (OCh 17); o a asegurar en Arte de pintas que el decoro es ala mayor purlección. (76) de: la pintura. Si se entiende que verosimilitud y decoro son nociones que ponen el aecnto en la necesaria coberencia de la obra de arte o el discurso - coherenciál tanto en su propia estructura y organización interior como en su relación con las crefncias más o menos aceptadas $y / 0$ areptables por la suciedad-se comprenderá fácilmente, y no resultará ni paradójico ni ridírulo, que en ese eqquema toda violación del decoro sea considerada como un atentado a la perfección del arle y, por último, como una muestra palpable bien de la incapacidad para ajustarse a las reglas y principios del arte por el artista, bien de su crasa ignorancia. En esa lógica, se entienden las tensuras de Mayans a Miguel Ángel -al que en otros aspectos elogia sin reparos - por haber incluido en el "Juicio Final», de asunto dogmático, una mentira pagana tan burda como la barca de Caronte; o a Lucas Jordán, por pintar en el «Sueño de Nabucodonosor*, de asunto histórico, una imagen de Morfeo. F incluso que critique la ausencia de vestidos *allí donde lo pide la honestidad* (AP 94), o el uso anacrónico de ropajes y vestimentas.

Siguiendo la división entre decoro interno y decoro externo apuntada por

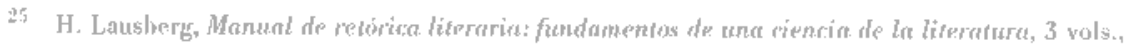
Matuid: Gredos, 1967, 2: 374 y 35.

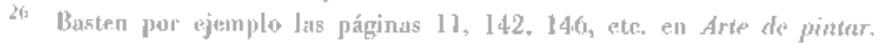


Cicerón en su Orator y matizada por Quintiliano en Institutiones, se refiere en El orador christiano a la necesidad de respetar el decoro externo, señalando que se debe aconsiderar qué pide el ticmpo, el lugar, el predicador, el oyente, dando a cada cosa aquello que su naturaleza pide, (17), trasladando casi al pie de la letra los cuatro elementos senalados por Cicerón: Lugar, tiempo, público y orador. Y en la Rhetórica alude al decoro interno afirmando que "la decencia consiste en apropiar las palabras y sentencias a las cosas que se quieren significar ${ }^{27}$, resumiendo con brevedad inmejorable la coherencia que se exige en la inventio, dispositio y elocutio. El hablar de las cosas naturales no se puede ajustar al decoro sin conocer y respetar lo que de ella se sabe por medio de las ciencias, ni mezclar la palabra de Dios o las cosas divinas con las fábulas paganas.

El uso de los diferentes estilos o caracteres del decir también debe ajustarse al decoro, o sea, proporcionarse em ciertos respetos a la persona que habla y a aquella con quien se habla y a la cosa de que se habla. (Rh 2:334), puesto que no puede emplear un mismo lenguaje el hombre culto y con ingenio que el ignorante, ni hablará igual un cientifico que um iletrato, por no insistir en que es del todo ilógico expresarse sin tener en cuenta la tapacidad del que tiscucha o el tema del que se habla. Pero tal vez la incjor articulatión de los componentes que configuran el concepto de decoro y su relación con otros aspectos de la producción artística la expresa Mayans en Arte de pintar, donde escribe:

\begin{abstract}
siendo el decoro un honesto uso de las cosas buenas o indiferentes, acomodado con decencia a la verdad de cllas y al rospeto que se debe a las personas de que se trata y con quienes se trata, se ha de procurar guardar con diligentisimo cuidado; porque lo que es contrario a la verdad y a la verosimilitud ofende al entendimiento; lo que es opuesto a las buenas costumbres irrila: lo que a lit buena crianza, desagrada (56).
\end{abstract}

El decoro es el principal fundamento que hace concordar lo que se representa y la naturaleza conocida de las cosas imitadas, sometido a criterios valorativos de carácter eminentemente social y supeditado al objetivo o finalidad que se le confiere al arte, la utilitas. Ya que lo que por naturaleza le corresponde a las cosas es a veces desconocido y aún incognoscible, o al menos no conocido con certeza, se vuelve de nuevo al criterio clave: la opinión común y la costumbre. Por eso, al hablar de los personajes alegóricos en comedias y tragedias, entiende que el decoro sería procurar que la persona que se finge diga aquello que diría si tuviera juicio y fuera capaz de hablar ( $R / 2: 114)$. La subjetividad, como se ve, no es creación de nuevo cuño de la estética kantiana (salvando todas las distancias).

27 G. Mayans, Rhetrice, 2 vols, Valencia: Herederos de Gcrónimo Conejos, 1757, 2: 35. Fin adelante cito con la sigla $R h_{\text {y }}$ y el número de volumen y página. 
Requisito previo para saber y poder guardar el decoro es poseer suma erudición. La familiaridad y frecuentación de las más diversas ramas del conocimiento, de las artes y ciencias, se presenta como elemento imprescindible para la perfección artística. Distingue Mayans dos tipos de erudición: una que es propia e intrínseca al arte mismo que practica un artífice concreto; otra que rodea, acompaña y ayuda al arte a perfeccionar con rigor y justeza la producción de la obra. Erudición interior y erudición exterior las llamará, definiendo la segunda - específicamente para la pintura- como la que stoma de otras artes para perfeccionar la suya. Tales son principalmente la física, la geometría, la simetría, la botánica, la anatomía, la fisiognomía, la óptica, la perspectiva, la topografía, la arquitectura, la ética o filosofía moral, la historia y otras artes, por no decir todas» ( $A P$ 114).

Evidente es que resulta de todo punto impensable suponer siquiera que se puede practicar con decoro un arte cualquiera careciendo de lo que nosotros llamaríamos algo más que una amplia y sólida «cultura general». En Mayans, un determinado nivel de sabiduría - nada elemental, a lo que se deduce--, fomentado y cultivado con estudios prolongados que no deben cesar, es un presupuesto universal -casi imperativo absoluto- para acometer la producción artística en cualquier campo. Claro que él no cree que la esencia del arte se reduzca a ser una manifestación de la erudición exterior. La misión cscncial de ésta es evitar los yruseros errores que con tanta asiduidad se observan en ropajes, referencias históricas a formas reales de la naturaleza.

Un tema se plantea así inexcusablemente. Un tema que clarifica el sentido de la imitación, de las condiciones que ésta debe satisfacer, del arte en suma. ¿Qué función debe realizar la obra? Mayans es buen hijo de su educación y de su ideología. Él nismo decía que cuando era aún niño, estudiante en Barcelona, llegó a aprenderse de memoria, junto a algunas odas, el Ars poetica de Horacio. Nada tiene de extraño, pues, que su visión fundamental de la finalidad del arte provenga directamente de ese texto horaciano y de la continua asimilación y transmisión de sus ideas a lo largo de la Edad Media y el Renacimiento. Las alusiones al binomio delectare et prodesse son reiterativas y proliferan por todos los textos mayansianos. Aún en una de sus últimas obras, Arte de pintar, lo retoma aplicándolo tanto a la poesía como a la pintura. Recuerda ahí las palabras de Horacio para afirmar que *si el asunto es voluntario, debe el pintor elegirle o útil por razón del objeto que piensa pintar, o virtualmente deleitoso $(A P 145)^{28}$, pero, expresando su convenci-

29 Pueden compararse estas palabras - como las de todos los partidarios de la utilidad del arte - con lis que había escrito fray Juan de Santo Tomás: el arte no depende en sus reglas y principios de la. rectitud de la voluntad $y$ de la recta intención del fin, sino que puede hacerse una perfecta obra de urte, aunque sea perversa la voluntad del artista citado en Menéndez Pelayo, HIE 1: 606. 
miento más íntimo, «el pintor más digno de alabanza será aquel que en los asuntos libres eligiere aquéllos en que sus pinturas no solamente agraden al alma divirtiendo su vista, sino que también instruyan al entendimiento, mejorando la voluntad. (AP 147).

De esta dualidad, de esta justificación teleológica bifurcada, sólo la faceta de la instrucción recibirá alguna precisión. En ningún sitio resume mejor su visión de la utilidad instructiva del arte que al escribirle a Cerdá Rico, en 1779: «deseo que solamente se impriman libros útiles para fomentar la piedad, o la erudición o la elocuencia ${ }^{29}$, donde queda perfectamente ordenado el conjunto y prelación de valores que confiere al arte. En relación estrecha con la visión de la espiritualidad que un Mayans más joven expuso en Espejo moral, la piedad es el máximo valor que puede tener una obra. Prueba evidente del peso que su religiosidad o, mejor si se quiere, que su moralidad religiosa ejerce sobre su eoncepción del arte son estas palabras en que aconseja que clodos los asuntos sean útiles para fomentar la devoción cristiana, para fortalecer la fe con la expresiva descripción de los tormentos que padecieron en defensa de ella los pacientísimos mártires... (AP, 182), 0 , al escribir en el erólogo a su Rhetórica que unicamente, pues, alabamos la retórica cristiana, esto es, la que persuade lo que es honesto y útil o a las personas particulares o a las familias o a las repúblicas o a todo el género humano» (1: XIV).

Manifestaciones similares abundan por doquier. Se niega, por ejemplo, a tratar de las fábulas milesias, sibaríticas y ciprias porque no las considera arte, ya que no merece tal nombre sla que no enseña cosas honestas ( $R h$ 1: 307). El mismo sentido tiene el deslizamiento semántico que hace de la palabra epastores* al hablar de la égloga y remitir a los Santos Patriarcas. La utilidad, impregnada de religiosidad, sin grandes desarrollos teóricos, no puede ser nunca compatible con la deshonestidad, ni con la irreligiosidad, ni menos aún con el anticatolicismo. El arte, por tanto, debe promover los méritos y virtudes de la religión católica, fomentar la devoción, reforzar a su manera y con sus medios el sentimiento religioso.

Lejos de Mayans la supeditación utilitaria del arte a la política, como había llegado a proponer d'Aubignac en el siglo anterior, y cuyo eco está todavía presente en palabras muy citadas de Luzán y otros españoles del dieciocho. El arte no debe someterse a la política, pero sí debe redundar en el fortalecimiento de la piedad. Del mismo modo que preconizaba una retórica cristiana, en Arte de pintar reconocerá que su objetivo al escribirlo ha sido oprocurar que la pintura sea muy conforme a la religión cristiana, de la manera que he intentado hacerlo en la filosofía moral* (AP 129), aludiendo a sus Institutionum Philosophice Moralis libri tres.

29 Revista de Archivos, Bibliotecas y Museos 9.13 (1905), 258. 
Además de la piedad y la erudición, la perfección del estilo aparece como factor esencial dentro de la eficacia pedagógica del arte. El estilo es instructivo en cuanto ayuda a que otros aprendan el mejor modo de escribir. Pero es, asimismo, elemento que incide decisivamente en el deleite que puede producir la obra. Ese torreno intermedio del estilo genera una evidente tensión en las opiniones de Mayans, Claramente se trasluce esa tensión, por ejemplo, en el juicio que enite sobre la Celestina, obra que no duda en considerar la mejor comedia anterior a las de Cervantes, repitiendo elogios semejantes en más de un lugar. Sin embargo, en una variante que introduce en la edición de 1739 de la Oración en alabanza, maliza: "la tan famosa como infame comedia de Calisto y Melibeas ${ }^{30}$. En esos dos calificativos, famosa e infume, resume perfeclamente la tensión a que me refería. Es un choque interior, nunca resuelto, entre un juicio puramente licerario y un juicio ideológicu-religioso. Su sensibilidad para captar las bellezas de la literatura es algo innegable y que el mismo Menéndez Pelayo le reconoce. Pero su religiosidad, no pacala, aunque sí rectora y omnipresente, no podía dejar de llegar hasta el terreno específico del estilo.

Es a partir de esa funcionalidad del arte, con sus matices contradictorios, donde hay que situar su actitud ante la elección de asuntos. El rechazo tajante y absoluto de las apinturas de objetos torpes y provocativos de la lujurias $(A P 97)$ se funda evidentemente en consideraciones morales y religiosas. Fis la perversidad de quienes pretenden la maldad de los demás, efacilitándoles por la vista complacencias viciosas» (AP 97), lo que las hace totalmente rechazables. El arte debe hacer cristianamente virtuoso a su contemplador, lector u oyente. En el mismo orden de valores, genéticamente relacionados con Vives, Cano, Malón de Chaide o fray Luis de León, rechaza lus libros de caballería, las novelas picarescas o las eróticas. La clección de asumtus, sin esté definitivamente predeterminada -aunque ya señalé Io que aconsejaba a los pintores-, tiene unos tochos bastante precisos.

En cuanto a la presencia en el arte de acciones o sucesos que puedan provocar horror, parece decantarse hacia la desdramatización horaciana, pero sin dejar de oscilar hacia la idea aristotélica de que hasta lo feo puede ser objeto de imitación si la perfección del arte con que está ejecutada lo compensa. Siguienda a $\mathrm{H}_{0^{-}}$ racio, cree que el deleite ano se ha de buscar en las nosas horrorosas, sino en las apacibles: el provecho es una instrucción más placentera que agradable ( $A P 53)$. Consecuentemente, Horacio preconizabá clidir los momentos álgidos de la acción trágica. Y, en su apoyo, Mayans recurre a la finalidad que Aristóteles atribuye a la tragedia: "si el fin de la tragedia es purgar el ánimo de las pasiones, opara qué se lo

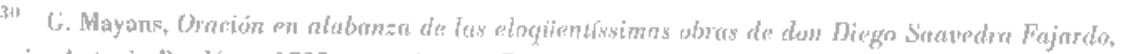
Valencia: Antonien Bordazar, 1725, pero vito por Ensetyos wmortos, Madrid: Juan de Zíñiga, $1730,115$. 
ha de inclinar a las violentas, habiéndose de apaciguar después?» (AP 53). Su postura no es, empero, definitiva, ya que inmediatamente se pregunta: «¿qué diremos de Séneca el trágico, que expuso en público a Medea matando a sus hijos?» (AP 54), y deja el interrogante en el aire. La conclusión que parece deducirse es que las acciones horrorosas que pueden provocar el pasmo no han de ser jamás imitadas. Pero, por otro lado, alo que parece cierto es que hay acciones horrorosas que pueden provocar la imitación* (54), y concluye su contrapunto al escribir que ael horror que causan algunos objetos pintados se corrije con el placer de lo bien que el pintor ha sabido representarlos. Fuera de que la pintura es una historia muda que debe copiar lo bueno y no omitir lo malo expresado con decoro* (54).

Como ocurre con otros aspectos del pensamiento mayansiano, sus ideas estéticas presentan falta de sistematización. Y ésa es la razón por la que apenas profundiza en conceptos clave de la estética clasicista, aparecen usos relativamente contradictorios de los mismos términos, ambivalencias, o ciertos problemas no están ni siquiera esbozados en sus escritos. Por lo demás, sus ideas se insertan, desde unas fuentes y con una intención a la vez concurrente y diversa, en la corriente dominante del siglo: el neoclasicismo. 